\title{
Antoni Bortnowsin
}

Uniwersytet im. Adama Mickiewicza w Poznaniu

iD

ORCID http://orcid.org/0000-0002-9963-1798

\section{ПОКОЛЕНИЕ ЗАКАТА СССР В РОМАНЕ АЛЕКСЕЯ НИКИТИНА VICTORY PARK}

\author{
THE GENERATION OF THE TWILIGHT OF THE USSR \\ IN ALEXEI NIKITIN'S NOVEL VICTORY PARK
}

The subject of this article is the presentation of Soviet reality in Alexei Nikitin's novel, Victory Park. The Russian-speaking Ukrainian writer presents in this work a wide panorama of the life of the inhabitants of left-bank Kiev in the first half of the 1980s. The generation of the late Stagnation Period lives in a world of discredited ideas, omnipresent absurdity, and hypocrisy. The aim of the article is to try to locate the sources of widespread apathy and hopelessness in Nikitin's novels, which, to a large extent, shape the young generation trying to find their way in a stagnant reality. The key to understanding the life attitudes of the protagonists is the analysis of the specificity of Kiev reality, which is the dominant feature of the world presented in the Victory Park.

Keywords: Alexei Nikitin, Victory Park, the generation of the decline of the USSR, Kiev, Russian-language literature of Ukraine

POKOLENIE SCHYŁKU ZSRR W POWIEŚCI

ALEKSIEJA NIKITINA VICTORY PARK

Tematem niniejszego artykułu jest obraz rzeczywistości radzieckiej w powieści Aleksieja Nikitina Victory Park. Utwór tego rosyjskojęzycznego pisarza ukraińskiego prezentuje szeroką panoramę życia mieszkańców lewobrzeżnego Kijowa pierwszej połowy lat 80 . XX wieku. Pokolenie późnego okresu zastoju funkcjonuje 
w świecie skompromitowanych idei, wszechobecnych absurdu i obłudy. Celem artykułu jest próba odpowiedzi na pytanie o źródła powszechnej apatii i beznadziei w powieści Nikitina, które w dużej mierze kształtują także młode pokolenie, próbujące odnaleźć swoją drogę w pogrążonej w marazmie rzeczywistości. Kluczem do zrozumienia postaw życiowych bohaterów jest analiza specyfiki kijowskiej rzeczywistości, będącej dominantą świata przedstawionego powieści Victory Park. Słowa klucze: Aleksiej Nikitin, Victory Park, pokolenie schyłku ZSRR, Kijów, rosyjskojęzyczna literatura Ukrainy

Victory Park - это третий роман современного русскоязычного киевского писателя Алексея Никитина'. Книга вышла в 2014 году и встретилась с широким признанием, войдя в длинный список «Национального бестселлера» и получив Русскую премию. Роман представляет собой панораму позднесоветской действительности в левобережном Киеве. Представляя несколько месяцев из жизни поколения заката СССР, Никитин воссоздал атмосферу того времени в многослойной, сложной, но вместе с тем органично цельной форме. Как сказано в одной из рецензий на книгу, «Victory Park предстает разросшейся лирической поэмой, галереей образов и случайных этюдов, скроенных в единую пеструю ткань» ${ }^{2}$ В этом романе

${ }^{1}$ Алексей Никитин, посвятивший большинство своих произведений родному Киеву, безусловно, является украинским писателем, но одновременно художник олицетворяет собой вызывающее определенные разногласия сложное явление - русскоязычную литературу современной Украины. Писатель сам неоднократно высказывался на эту тему, в частности, в интервью для «Радио Свобода»: «Есть украинская культура, украинская литература, есть литература Украины - это не тождественные вещи. Украинская литература - это часть литературы Украины. Точно так же, как русская, еврейская [...] и польская [...]. Русская литература, с одной стороны - литература Украины, с другой - часть большой русской литературы. Такое пересекающееся пространство двух культур очень интересно. Сильное влияние украинской литературы на русскую чувствуется. Это нельзя называть в чистом виде 'русский мир' на Украине, он все равно другой, русская литература другая, она подвержена влияниям, которые делают ее очень интересной, тут есть что-то новое». Е. Фанайлова, Богема на баррикадах. Часть 11. Писатель Алексей Никитин // «Радио Свобода», 19.08.2014, https://www.svoboda.org/a/26537627.html (18.08.2020).

${ }^{2}$ T. Сохарева, Вечера на хуторе близ промзоны // «Газета.Ru», 14.05.2014, https://www.gazeta.ru/culture/2014/05/14/a_6032653.shtml (13.08.2020). 
с открытой композицией, подчеркивающей неопределенность представленных времен, ни одна сюжетная линия не доминирует, все они переплетаются, формируя ощущение «ленивой» полифонии, - читатель словно бродит без определенной цели вокруг заглавного Парка Победы. Можно сказать, что главным героем Victory Park Никитин назначил свой родной город - Киев, о чем прямо заявил в одном из интервью:

$\mathrm{B} \mathrm{XX}$ веке в русской литературе появилось два больших романа о Киеве: Белая гвардия Михаила Булгакова и Бабий Яр Анатоля Кузнецова. О послевоенном городе, преимущественно о 1960-х, писал любимый киевлянами Виктор Некрасов, но его Записки зеваки и Саперлипопет - это повести. Романа о последних, предзакатных советских десятилетиях не было. Я буду рад, если Victory Park сумеет заполнить эту лакунуз

Симптоматично, что свой роман Никитин соотносит с произведениями авторов, ассоциируемых с русской литературой ${ }^{4}$, доказывая тем самым свою причастность к ее традициям, совмещающуюся в его лице со статусом украинского писателя.

Анализируя в нашей статье образ предперестроечного Киева в романе Victory Park, мы будем исходить из социологического подхода к понятию по колен ие, согласно которому «поколения как большие социальные общности являются продуктом конкретно-исторических условий и поэтому представляют собой мезоуровневые социальные образования» ${ }^{5}$. Следовательно, поколение объединяет определенный габитус, являющийся устойчивой системой предрасположенностей к восприятию действительности ${ }^{6}$. Основоположником

\footnotetext{
${ }^{3}$ Е. Серебрякова, Алексей Никитин: Я мифологизирую Киев, и делаю это сознательно, http://write-read.ru/interviews/1436 (18.08.2020).

${ }^{4}$ В украинской литературе XX века киевская тема присутствует, например, в известном романе Валерьяна Пидмогильного Город (Micmo, 1928).

5 Л.Ю. Пушина, Поколение как социокультурная общность // «Вестник Нижегородского университета им. Н.И. Лобачевского. Серия Социальные науки» 2011, № 3, с. 33.

${ }^{6}$ См. ее же, Габитус как атрибут поколенческой общности // «Вестник КГУ им. Н.А. Некрасова» 2012, № 2, с. 184-187.
} 
социологического подхода к проблеме поколений стал Карл Мангейм - его работа Проблема поколений (Das Problem der Generationen, 1928) стала в нашем случае ключевой для анализа романа Victory Park. Именно в ней сказано, что «об общности местоположения поколения мы вправе говорить только тогда, когда современники в состоянии участвовать в определенном общем опыте в качестве интегрированной группы» ${ }^{7}$ В книге Алексея Никитина все герои глубоко погружены в позднесоветскую реальность - она определяет их судьбу, формирует способ мышления и, несомненно, является интегрирующим фактором, о котором писал в своей работе Мангейм.

События, представленные в книге Никитина, разворачиваются в основном в левобережном Киеве - части города, возникшей уже в советское (и послевоенное) время и потому являющейся своего рода символом своего времени. Уже в начале романа повествователь указывает на специфику левого берега, всегда находящегося немного в стороне от исторических потрясений центральной части Киева:

$\mathrm{Bce}$, о чем потом писал Нестор, все, что рассказывали скучающим школьникам учителя истории, происходило на правом берегу. [...]

Левый берег - пасынок истории. На левом под теплым солнцем цвели заливные луга, пахли смолой и земляникой сосновые леса, жирели кулики на болотах и только кое-где появились вдоль дорог небольшие села с названиями, подсказанными их обитателям местной флорой: Осокорки, Вишняки, Березняки, Очереты... ${ }^{8}$

Получается, что левобережный Киев жил своей, довольно обособленной жизнью, словно следуя украинской поговорке: моя хата с краю - нічого не знаю9 ${ }^{9}$ В некоторой степени он мог

\footnotetext{
${ }^{7}$ К. Мангейм, Проблема поколений // его же, Очерки социологии знания. Проблема поколений. Состязательность. Экономические амбиции, перев. Е.Я. Додин, ИНИОН РАН, Москва 2000, с. 30.

${ }^{8}$ А. Никитин, Victory Park, Ад Маргинем Пресс, Москва 2014, с. 22. Все дальнейшие цитаты приводятся по данному изданию с указанием в скобках номера страницы.

${ }^{9}$ В произведении прямо сказано, что, в отличие от самого Киева, который мог быть Польшей, а мог быть и Россией, «небольшие села левого берега,
} 
затем стать символом всей советской Украины начала 80-х, которая, оставаясь ключевой составляющей СССР, все меньше ощущала власть слабеющего центра империи и все больше осознавала безысходность своего существования. В жизни киевлян на левом берегу Днепра особенно отчетливо чувствовалась безнадежная тупиковость предперестроечных лет. Никитин на страницах своего романа использует приемы, подчеркивающие атмосферу позднего периода застоя. Уже в самом начале произведения описание интерьера киевской квартиры позволяет погрузиться в депрессивную реальность позднего СССР:

Пахло пылью, несвежей одеждой. Пахло нелюбимым неухоженным жильем, домом, где живут в спешке, без удовольствия и без внимания к милым пустякам, способным если не сделать жизнь осмысленной, то хотя бы скрасить ее унылую бесприютность (с. 7).

Настроение в романе строится также с использованием описаний природы. Действие произведения проходит на фоне городских пейзажей, которые у Никитина безмятежны, спокойны. Киевская природа в произведении лишена стихийности, и с приближением летней жары становится все более «ласковой», медлительной и сонливой:

Внизу зеленел тихий киевский двор, еще не выгоревший, не выцветший до желтизны под раскаленным летним солнцем. В тени шестнадцатиэтажных башен мирно поспевали абрикосы и вишни, кричали о чем-то дети, дворники поливали асфальт из шлангов (с. 12).

Природа в какой-то степени также дополняет и усиливает ощущение застоя в советской жизни. Лишь в конце произведения звучит прогноз погоды, который можно понять, как предзнаменование конца прежней - надоевшей, но размеренной, стабильной и предсказуемой - жизни:

Начинался октябрь, метеорологи усердно и убедительно обещали холодный фронт, сопутствующие ему дожди, шквальный порывистый ветер и резкое снижение температуры, но погода упрямо, изо всех сил держа-

затерявшиеся между старицами Днепра и безымянными лесными болотами, затаившиеся в прибрежных камышах рядом с густыми сосняками, всегда оставались Украиной» (с. 25). 
лась солнечная. Заканчивались последние теплые дни тихой и сонной осени (с. 194).

Несмотря на яркие моменты в жизни героев, в целом именно ощущение апатии характерно для населения левобережного Киева, которое представляет собой картину советского общества в миниатюре. Описывая восточную часть столицы УССР, автор, по сути, изобразил всю специфику советской действительности периода позднего застоя, отразившегося в жизни поколения начала 80-х гг. При этом, с помощью киевской реальности, Никитину удалось показать не только позднесоветскую жизнь, но и механизмы, десятилетиями формировавшие лицо советского общества. На примере левобережного Киева видно, каким образом в огромном «плавильном котле империи» люди, олицетворяющие новое, советское время сталкивались с населением, живущим согласно традиционным, еще дореволюционным ценностям. В итоге обе группы сформировали своеобразную мозаику «осиротевшего» поколения, которое потеряло связь с прошлым, но так и не смогло воплотить в себе идеалы «советского человека»:

Киев пришел в эти места после войны, неожиданно и стремительно. [...] Левобережные слободы и села оказались в кольце. Одно за другим они исчезали, оставляя новым районам города свои названия. И только Очереты, давнее рыбачье село [...] неожиданно устояло перед массированной атакой новостроек (с. 25).

В романе Никитин затрагивает существенный вопрос национального сознания в позднесоветском обществе и показывает причины, по которым в таких местах, как левобережный Киев, люди не отождествляли себя с украинской культурой. Жители Комсомольского массива, возникшего с нуля на месте украинских приднепровских сел, происходили из разных уголков СССР - они «не видели ни прежнего Крещатика, ни довоенной площади Калинина. Не знали они и Украины, считая ее той же Россией, только разве что немного другой и какой-то странной» (с. 26).

Советская идеология, подпитываемая во многом пропагандой, направляющей внимание людей в сторону «светлого 
будущего», дополнительно усиливала разобщенность послевоенного поколения с прошлым, которая с годами лишь усугублялась. В итоге для многих советских граждан культурное наследие и традиции территорий, на которых им выделяли квартиры, не имели никакой ценности:

Какой может быть прок в этих допотопных деревянных развалюхах, коровниках, старых рыбачьих складах и смешной церкви? Страна уходит в космос - на Луну, на Венеру, покоряет мирный термояд! Что общего у нас с неприглядным деревянным прошлым?! Все эти хибары простоят здесь от силы еще год-другой, а потом на их месте появятся высотные новостройки, еще лучше тех, которыми застроен Комсомольский массив (c. 27).

Большевики, однако, несмотря на изначальный энтузиазм, в итоге не достигли своих целей и выдохлись. Так же, как и строители новых массивов на левом берегу Днепра, которые не сумели справиться с болотистой местностью и так до конца ее и не осушили. Героям романа Никитина пришлось жить во времена, когда стало ясно, что ни строители коммунизма, ни киевские архитекторы не доведут до конца свои грандиозные планы. Советский эксперимент оказался неудачным, но все еще оставалось неясным, чем можно было заполнить образовавшуюся при его создании пустоту. По крайней мере, этого не знали представители поколения, изображенного Никитиным в романе Victory Park. Их голосом становится зарабатывающий торговлей самиздатом Жорик, произнесший в предпоследней главе следующие слова: «Вакуум - настоящий символ будущего. Нам еще только предстоит заполнить тот, что уже есть [...]» (с. 195).

Именно с проблемой отсутствия идей сталкиваются герои произведения, осознавшие, что «старое» уже морально обанкротилось, но не умеющие предложить ничего состоятельного взамен. Единственной группой, у которой есть четко сформулированные цели и ярко выраженное желание преодолеть всеобщий застой, является в романе отряд вернувшегося из Афганистана Калаша. Предводитель группы молодых ветеранов, желающих возродить идеалы коммунизма, в пламенной 
речи объясняет Пеликану, одному из главных героев романа, свое видение ситуации в стране:

Ленина продали, не вынося из мавзолея. Маркса переврали и забыли! Мы должны были строить коммунизм, в этом смысл существования Советского Союза. А что построили вместо коммунизма? [...] Государство воров разного калибра и тухлых лжецов. Они говорят «коммунизм», а сами строят дачи. [...] За коммунизм нужно бороться, идти в бой, не жалея жизни и не боясь крови! Кто сейчас на это способен? Настоящих коммунистов в Советском Союзе не осталось, власть в стране захватили обыватели. А обывателям все безразлично, кроме их теплых и глубоких нор. [...] Стране нужна новая революция. И она начнется очень скоро (с. 137).

Очевидно, что Калаш и его единомышленники не предлагают реального движения вперед - они, не усвоив уроков истории, стремятся лишь к повторению ошибок прошлого. Повествователь, объясняя бесперспективность романтичных порывов Калаша, обращается к идее бессмысленности «русского бунта», одной из сквозных тем русской литературы, начатой еще Александром Пушкиным в Капитанской дочке:

И если вдруг каким-то невозможным чудом кому-нибудь, допустим, Калашу удастся еще раз подбросить монету, то, крутанувшись в воздухе десяток раз, она упадет точно так же, реверсом вверх. Так падали монеты всех революций, давя всех, кто, к своему несчастью, оказался рядом (c. 138).

Симптоматично, что Пеликан, отчетливо осознает явные недостатки идеологии Калаша, но не умеет противопоставить «бессмысленному и беспощадному русскому бунту» ничего более состоятельного. А главное - не хочет, не чувствует такой потребности:

Конечно, на карты советских вождей, прокладывавших пути к коммунизму, не нанесли болото, в которое занесло страну. Тут он прав, но правота Калаша была безразлична Пеликану, потому что коммунизм его не интересовал. Пеликан не верил ни в какой другой коммунизм [...] (с. 137).

Нежелание активно менять действительность касается и других героев, которые приспособились к полной абсурдов и лишений советской жизни, хотя она уже надоела практиче- 
ски всем. Важно отметить, что утомленность советской системой отнюдь не касается у Никитина политических и национальных проблем. Люди в романе Victory Park устали от того, что им не давали нормально жить, они отказывались понимать и принимать вводимые советской властью ограничения. Свое недовольство открыто выражали даже пьяницы, проводящие целые дни у магазина:

- Долбанные суки, - продолжал негодовать народ, адресуясь на этот раз к руководству Днепровского райгастрономторга и всей советской торговой системе, не позволяющей простому человеку опохмелиться, когда ему это нужно, а не дожидаться в муках дозволенных триста шестьдесят первым постановлением Совмина СССР одиннадцати часов утра (c. 17).

Никитин в романе обращает внимание на важную закономерность - в поколении позднего СССР испарилась не только вера в советские идеи, но и страх, с помощью которого большевики десятилетиями удерживали власть. Вместо прежнего трепета остались лишь раздражение и негодование:

Между тем, в ложь большевиков больше не верят, их самих не боятся, и если ничего не изменится, эта власть, какой бы прочной она ни казалась, скоро развеется по ветру липкими клочьями, как туман над Чертороем. Либо они опять отстроят лагеря и загонят в них полстраны, либо весь их Советский Союз рухнет, как рухнула когда-то Николашкина Россия, едва народ перестал бояться царя и устал верить в Бога (с. 142).

Усталость от советской реальности касалась и упомянутых выше алкоголиков, «кочующих» у магазина, и предприимчивых граждан, замечающих абсурдные принципы, по которым функционировала советская экономика. Для всех стало очевидным, что СССР оказался в тупике. Это понимал предприимчивый Леня Бородавка, который мог сделать блестящую карьеру, «но существовать в пустой, мертвящей тоске и скуке чиновничьего мира было выше его сил» (с. 34). На примере этого персонажа Никитин показал, что советская система сама лишила себя будущего, не позволяя наиболее предприимчивым и целеустремленным представителям поколения позднего застоя предпринять хоть какие-то попытки преодо- 
леть абсурдные принципы советской экономики. Бородавка, желая действовать, устроился инженером на завод и внедрил более эффективную схему производства:

Удивительным в этой истории было то, что пользу эксперимента, предложенного Бородавкой, понимали все. Даже горластые горкомовцы понимали. Объединение экономило, значит, экономило и государство. [...] Но это в идеале, в тех правильных схемах, которые Леня Бородавка изучал в родном Легпроме. А в социалистическом плановом хозяйстве все иначе, здесь работают другие схемы, и определяет все не экономическая целесообразность, вовсе не она (с. 35).

В итоге нововведения не вписались в планы руководства, которое каким-либо инновациям предпочло работу по старым схемам. Пример Бородавки показывает, как советская система, перешедшая от стабильности к стагнации, начала работать на самоуничтожение. Самые активные граждане, желая реализовать себя, были вынуждены уходить в тень и вести двойную жизнь: легально работать на госслужбе, создавая видимость послушной реализации принципов плановой экономики, а параллельно «фарцевать» и участвовать в коррупционных схемах. В романе Victory Park ясно видно, насколько фасадным было декларируемое официальное равенство, скрывающее истинную картину расслоенного общества всеобщего дефицита, в котором узкая группа населения жила комфортной, даже роскошной жизнью, в то время как подавляющему большинству предлагались пустые прилавки. Герои романа Никитина понимают, что честным трудом добиться ничего не получится, так как жизнь перестала развиваться по законам логики. С этим не мог смириться товарищ Бородавки - Гончаренко, после того, как следствие узнало, что оба они замешаны в нелегальное перевыполнение плана, приравниваемое к хищению социалистической собственности:

Почему мы с тобой преступники? Мы кого-то убили или ограбили? Мы что-то украли? Почему мы должны прятаться и бояться ОБХСС? Мы что, похитили какую-то социалистическую собственность, скажи мне? Ведь нет же. Мы с тобой ничего не украли, а только добавили, хотя могли этого 
не делать и жили бы спокойно. Я бы давал план, получал свои премии и плевал в потолок (с. 113).

Более опытный Бородавка в ответ лишь с грустью констатирует суть советской системы: «Ты ищешь смысл, а смысла в этом нет - когда-то он был, но давно выветрился. Осталась традиция» (с. 114). Словами Бородавки, несомненно, можно подытожить всю позднесоветскую действительность, представленную в романе Никитина, - она превратилась в лишенную содержания форму, традицию, культивируемую лишь за неимением альтернативы.

Губительное влияние советской системы сказывалось отнюдь не только на экономической жизни населения. В романе Victory Park отчетливо видна духовная пустота поколения позднего СССР, лишенного традиционных идей и ценностей, в частности, семейных. Симптоматично, что это касается практически всех героев. Десятилетия советской власти привели разных людей в один и тот же тупик, вне зависимости от происхождения и классовой принадлежности. Ярче всего это видно на примере молодого поколения, и особенно Ивана Багилы, дед которого сражался в годы Гражданской войны в отрядах Махно, и его друга Пеликана, потомка дореволюционной интеллигенции, внука приват-доцента. Оба парня теряют связь с прошлым, но так и не находят пути в будущее. На примере Багилы, выросшего в вымышленном селе Очереты, окруженном новостройками левобережного Киева, Никитин показывает явление разрыва цепи поколений даже там, где люди веками жили на одной и той же территории. Символичными в данном контексте становятся отношения молодого парня с его дедом - Максимом. Внук, при всем уважении к старому Багиле, не знает и не понимает его:

Для Ивана, который вырос рядом с дедом Максимом и мог наблюдать его в разных обстоятельствах, тот оставался фигурой такой же загадочной и непонятной, как для любого гостя. [...] Он догадывался, что дед Максим чего-то ждет от него, но не понимал, чего именно. Это так неприятно, не оправдывать чужих надежд. Особенно если не знаешь, что от тебя хотят (с. 40). 
Теряет связь с прошлым также друг Багилы - Пеликан, что символично выражается в продаже остатков семейной библиотеки:

Сады и парки были бабушкиным наследством. Правда, от ее сказочной библиотеки, занимавшей когда-то целый зал в старой квартире на углу Владимирской и Большой Житомирской, давно уже остались считанные тома. К родителям Пеликана их попало только шесть. Теперь осталось пять (с. 51).

Неслучайно Пеликан продает бабушкины Сады и парки ради покупки пары кроссовок Рuma для любимой девушки - происходит подмена ценностей, всеобщий дефицит ведет к культурному вырождению. В итоге обувь Пеликан так и не получает, а девушка его бросает - парень напрасно жертвует семейным наследием и остается ни с чем. В данной ситуации можно увидеть символическое отражение трагедии молодого поколения тех лет, теряющего остатки своего прошлого в тщетных попытках найти счастье и устроить себе жизнь.

Симптоматично, что эрозия межпоколенных связей касается практически всех героев романа. Беспомощные и потерянные родители не могут помочь детям найти жизненные ориентиры, что лишь усугубляет ощущение тупиковости молодого поколения середины 80-х гг. Очередная вечная тема русской литературы - взаимоотношения «отцов и детей» - получает в романе Никитина свое очередное воплощение. Молодые герои и их родители не понимают друг друга и в итоге не могут оказать друг другу поддержку.

Наиболее ярко это видно на примере трех поколений рода Багил. Прилетев на похороны Максима, «старого», его сын Семен не только не узнает родные места, но и собственного сына Ивана. Над гробом отца он также ощущает лишь пустоту: «Семен Багила десять минут помолчал у гроба отца, попытался собраться с мыслями, но в голове лишь гулко звенела пустота. Ничего кроме усталости после трех перелетов и непредвиденной схватки за билет во Внуково он не испытывал» (с. 182). Сыну Семен может предложить лишь идти 
по его следам: «Я тебе коротко скажу: сворачивай все свои дела и переезжай ко мне. Закончишь институт по профилю и впишешься в систему как свой» (с. 183). В итоге молодой Багила, не зная, чего ему надо от жизни, так и делает. Таким образом он олицетворяет явление, о котором в своей работе писал Мангейм:

Несостоятельные в плане выработки собственной энтелехии поколения склонны, там, где это возможно, примыкать к предыдущему поколению, уже выработавшему удовлетворительную форму $[\ldots]^{10}$.

Отчужденность ощущается также в отношениях Пеликана с его близкими. Родители героя, давно закрывшиеся в мире археологических раскопок, словно самоустранились, оставляя сына в пустой киевской квартире. Они не могли предложить молодому человеку ничего, кроме однообразной жизни среди тоскливых пейзажей Черниговщины:

В экспедиции у родителей ничего не менялось годами. [...] Все его детство прошло в залитых дождевой водой черниговских раскопах. Это было интересно, это было не скучно, но он точно знал, что, не вырвавшись отсюда, он так и останется ребенком Пеликанов (с. 185).

Пеликан как представитель молодого поколения чувствует, что не может жить так же, как его родители, но собственного пути он на страницах романа так и не находит. Его проблему, скорее всего, не сможет также решить служба в Афганистане, куда в конце романа Пеликан отправляется по собственному желанию. Симптоматично, что в книге не указано имя героя, который так и остается лишь очередным представителем рода Пеликанов. Он становится в некоей степени воплощением тургеневской разновидности «лишнего человека», неспособного активно действовать, смирившегося с судьбой. На этот факт обращает внимание его девушка:

Ирка была из тех, кто в любой ситуации видит не данность, но лишь начальное условие, которое всегда можно изменить в свою пользу, поэтому

${ }^{10}$ К. Мангейм, Проблема поколений..., с. 42. 
спокойное безразличие Пеликана ее злило, а в его объяснениях она видела только слабость человека, сдавшегося прежде времени (с. 197).

В итоге Ирка, разочарованная Пеликаном, заявляет, что его не любит и ждать его из армии не будет - герой проваливает испытание любви в истинно тургеневском стиле. Симптоматично, что Ирка (кстати, так же, как и многие тургеневские девушки) сама также не знает, куда направить свою энергию. Недостаток жизненных ориентиров опять во многом вытекает из отсутствия взаимопонимания между героиней романа и ее родственниками. Семнадцатилетняя девушка не считается с бабушкой, не уважает отчима и открыто конфликтует с матерью.

Елена [мать Ирки - А.Б.] видела, что у Ирки в точности ее характер, - значит, им не ужиться ни за что. Еще год, от силы два, и они сперва разругаются, а после на всю жизнь возненавидят друг друга. Словно готовясь встретить это близкое будущее уже сейчас, Елена не уступала дочери ни в чем, жестко подчиняя ее, навязывая свою волю даже в мелочах (с. 83).

Отношения матери с дочерью, превратившиеся в подобие животного соперничества, становятся очередным доказательством того, насколько сильной эрозии подверглись традиционные семейные ценности в реальности, представленной в романе Victory Park.

В результате молодое поколение предперестроечного СССР оказывается в ощущаемой всеми пустоте, в которой исчезла вера в идеалы, традиции утрачены, стремиться некуда, друзья могут предать, настоящей любви нет, профессиональное развитие невозможно, а самые близкие люди не понимают друг друга и не могут друг другу ничего предложить. Герои Никитина относятся к т. н. поколению ухода, о котором пишет в своей работе Петр Ореховский: «Центральной проблемой этого поколения является поиск способа жизни в полностью фальшивом социальном устройстве» ${ }^{11}$. Система, представлен-

${ }^{11}$ П.А. Ореховский, Поколенческая динамика и новейшая история СССРРоссии (1950-2004 г2.) // «Мир России. Россия в исторической ретроспективе» 2009, № 4, с. 37. 
ная Никитиным, все еще живет по инерции, но уже понятно, что будущего у нее нет - она себя изжила и при малейшем потрясении рухнет, так как исчерпала свой потенциал и нет никого, кто встанет на ее защиту. Ощущая безысходность, герои Victory Park все еще не видят способов преодоления своего тупикового положения. В конце произведения одинаково растерянными оказываются и Пеликан, и его друг Багила. Оба молодых человека покидают родной Киев и обоих ждет туманное, неопределенное будущее в далеких краях: Пеликан отправляется в Афганистан, а Багила - на Русский Север. «Жернова» советской системы до последнего момента продолжают работать, отрывая людей от их родной почвы. Представленный в романе Victory Park образ предперестроечного поколения в киевских реалиях, безусловно, позволяет лучше понять проблемы, с которыми столкнулась уже независимая Украина, пытающаяся преодолеть советское наследие.

\section{REFERENCES}

Fanaylova, Yelena. "Bogema na barrikadakh. Chast' 11. Pisatel' Aleksey Nikitin." Radio Svoboda, https://www.svoboda.org/a/26537627.html. Accessed 18 Aug. 2020 [Фанайлова, Елена. "Богема на баррикадах. Часть 11. Писатель Алексей Никитин.” Радио Свобода, https://www.svoboda.org/a/26537627. html. Дата обращения: 18 августа 2020].

Mangeym, Karl. "Problema pokoleniy." Ocherki sotsiologii znaniya. Problema pokoleniy. Sostyazatel'nost'. Ekonomicheskiye ambitsii. Transl. Dodin, Yefim Ya. Moskva: INION RAN, 2000 [Мангейм, Карл. “Проблема поколений.” Очерки соииологии знания. Проблема поколений. Состязательность. Экономические амбиции. Перев. Додин, Ефим Я. Москва: ИНИОН РАН, 2000].

Nikitin, Aleksey. Victory Park. Moskva: Ad Marginem Press, 2014 [Никитин, Алексей. Victory Park. Москва: Ад Маргинем Пресс, 2014].

Orekhovskiy, Petr A. "Pokolencheskaya dinamika i noveyshaya istoriya SSSRRossii (1950-2004 gg.)." Mir Rossii. Rossiya v istoricheskoy retrospektive, no. 4, 2009: 37-65 [Ореховский, Петр А. “Поколенческая динамика и новейшая история СССР-России (1950-2004 гг.).” Мир России. Россия в исторической ретроспективе, по. 4, 2009: 37-65].

Pushina, Lada Yu. "Gabitus kak atribut pokolencheskoy obshchnosti." Vestnik KGU im. N.A. Nekrasova, no. 2, 2012: 184-187 [Пушина, Лада Ю. “Габитус 
как атрибут поколенческой общности.” Вестник КГУ им. Н.А. Некрасова, № 2, 2012: 184-187].

Pushina, Lada Yu. "Pokoleniye kak sotsiokul'turnaya obshchnost." Vestnik Nizhegorodskogo universiteta im. N.I. Lobachevskogo. Seriya Sotsial'nyye nauki, no. 3, 2011: 28-34 [Пушина, Лада Ю. "Поколение как социокультурная общность." Вестник Нижегородского университета им. Н.И. Лобачевского. Серия Социальные науки, № 3, 2011: 28-34].

Serebryakova, Yelena. "Aleksey Nikitin: Ya mifologiziruyu Kiyev, i delayu eto soznatel'no." http://write-read.ru/interviews/1436. Accessed 18 Aug. 2020 [Серебрякова, Елена. “Алексей Никитин: Я мифологизирую Киев, и делаю это сознательно.” http://write-read.ru/interviews/1436. Дата обращения: 18 августа 2020].

Sokhareva, Tat'yana. "Vechera na khutore bliz promzony." Gazeta.Ru, 14.05.2014, https://www.gazeta.ru/culture/2014/05/14/a_6032653.shtml. Accessed 13 Aug. 2020 [Сохарева, Татьяна. "Вечера на хуторе близ промзоны." Газеma.Ru, https://www.gazeta.ru/culture/2014/05/14/a_6032653.shtml. Дата обращения: 13 августа 2020]. 